\title{
$41 \mathrm{GHz}$ and $10.6 \mathrm{GHz}$ low threshold and low noise InAs/InP quantum dash two-section mode-locked lasers in $L$ band
}

Dontabactouny, M.; Piron, R.; Klaime, K.; Chevalier, N.; Tavernier, K.; Loualiche, S.; Le Corre, A.; Larsson, David; Rosenberg, C.; Semenova, Elizaveta

Total number of authors:

11

Published in:

Journal of Applied Physics

Link to article, DOI:

$10.1063 / 1.3677976$

Publication date:

2012

Document Version

Publisher's PDF, also known as Version of record

Link back to DTU Orbit

Citation (APA):

Dontabactouny, M., Piron, R., Klaime, K., Chevalier, N., Tavernier, K., Loualiche, S., Le Corre, A., Larsson, D., Rosenberg, C., Semenova, E., \& Yvind, K. (2012). $41 \mathrm{GHz}$ and $10.6 \mathrm{GHz}$ low threshold and low noise InAs/InP quantum dash two-section mode-locked lasers in L band. Journal of Applied Physics, 111(2), https://doi.org/10.1063/1.3677976

\section{General rights}

Copyright and moral rights for the publications made accessible in the public portal are retained by the authors and/or other copyright owners and it is a condition of accessing publications that users recognise and abide by the legal requirements associated with these rights.

- Users may download and print one copy of any publication from the public portal for the purpose of private study or research.

- You may not further distribute the material or use it for any profit-making activity or commercial gain

- You may freely distribute the URL identifying the publication in the public portal 


\section{AIP Appilied Physics}

\section{$41 \mathrm{GHz}$ and $10.6 \mathrm{GHz}$ low threshold and low noise InAs/InP quantum dash two-section mode-locked lasers in $L$ band}

M. Dontabactouny, R. Piron, K. Klaime, N. Chevalier, K. Tavernier et al.

Citation: J. Appl. Phys. 111, 023102 (2012); doi: 10.1063/1.3677976

View online: http://dx.doi.org/10.1063/1.3677976

View Table of Contents: http://jap.aip.org/resource/1/JAPIAU/v111/i2

Published by the American Institute of Physics.

\section{Related Articles}

Kinetic analysis of two dimensional metallic grating Cerenkov maser Phys. Plasmas 18, 084508 (2011)

The self-consistent nonlinear theory of electron cyclotron maser based on anomalous Doppler effect Appl. Phys. Lett. 98, 261502 (2011)

Cavity quantum electrodynamics for photon mediated transfer of quantum states

J. Appl. Phys. 109, 113110 (2011)

A method of suppressing mode competition in a coaxial localized-defect Bragg resonator operating in a higherorder mode

Phys. Plasmas 18, 064506 (2011)

Strong coupling between a photonic crystal nanobeam cavity and a single quantum dot Appl. Phys. Lett. 98, 173104 (2011)

\section{Additional information on J. Appl. Phys.}

Journal Homepage: http://jap.aip.org/

Journal Information: http://jap.aip.org/about/about_the_journal

Top downloads: http://jap.aip.org/features/most_downloaded

Information for Authors: http://jap.aip.org/authors

\section{ADVERTISEMENT}
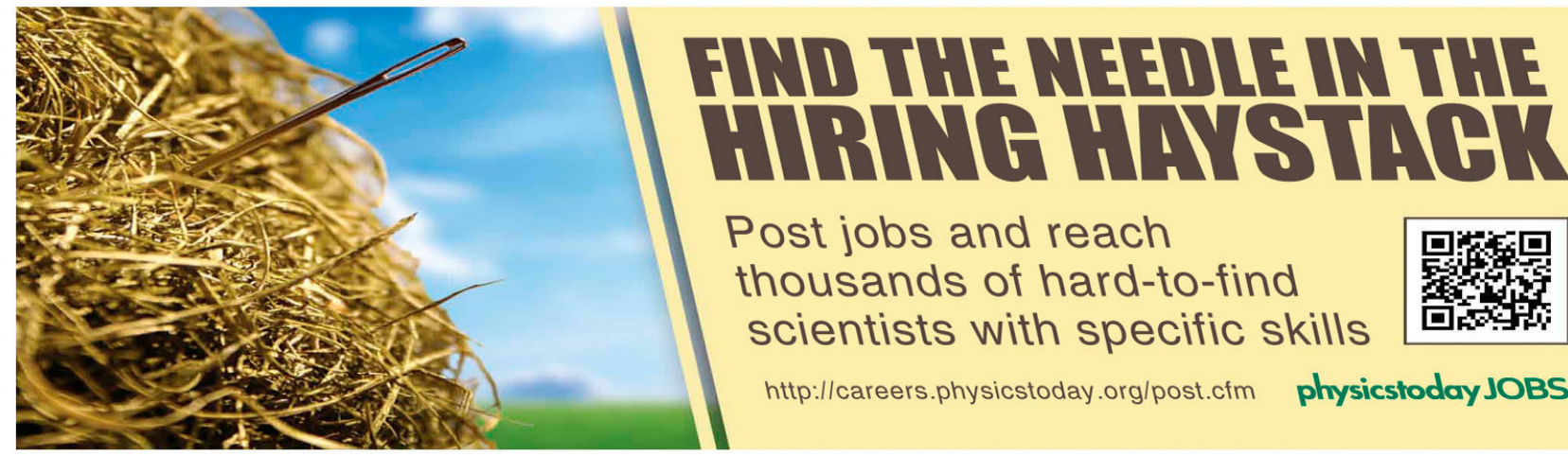

http://careers.physicstoday.org/post.cfm

physicstoday JOBS 


\title{
$41 \mathrm{GHz}$ and $10.6 \mathrm{GHz}$ low threshold and low noise InAs/InP quantum dash two-section mode-locked lasers in $L$ band
}

\author{
M. Dontabactouny, ${ }^{1}$ R. Piron, ${ }^{1}$ K. Klaime,${ }^{1}$ N. Chevalier, ${ }^{1}$ K. Tavernier,${ }^{1}$ S. Loualiche, ${ }^{1, a)}$ \\ A. Le Corre, ${ }^{1}$ D. Larsson, ${ }^{2}$ C. Rosenberg, ${ }^{2}$ E. Semenova,${ }^{2}$ and K. Yvind ${ }^{2}$ \\ ${ }^{1}$ Université Européenne de Bretagne, INSA, Rennes, CNRS, UMR 6082, Foton, France \\ ${ }^{2}$ Department of Photonics Engineering, Technical University of Denmark, Ørsteds Plads, \\ 2800 Kongens Lyngby, Denmark
}

(Received 22 September 2011; accepted 16 December 2011; published online 18 January 2012)

This paper reports recent results on InAs/InP quantum dash-based, two-section, passively modelocked lasers pulsing at $41 \mathrm{GHz}$ and $10.6 \mathrm{GHz}$ and emitting at $1.59 \mu \mathrm{m}$ at $20^{\circ} \mathrm{C}$. The $41-\mathrm{GHz}$ device (1 mm long) starts lasing at $25 \mathrm{~mA}$ under uniform injection and the $10.6 \mathrm{GHz}$ (4 mm long) at $71 \mathrm{~mA}$. Their output pulses are significantly chirped. The 41-GHz laser exhibits 7 ps pulses after propagation in $60 \mathrm{~m}$ of a single-mode fiber. The 10.6-GHz laser generates one picosecond pulses with $545 \mathrm{~m}$ of a single-mode fiber. Its single side-band phase noise does not exceed $-80 \mathrm{dBc} / \mathrm{Hz}$ at $100 \mathrm{kHz}$ offset, leading to an average timing jitter of $800 \mathrm{fs}$. (C) 2012 American Institute of Physics. [doi:10.1063/1.3677976]

\section{INTRODUCTION}

Monolithic mode-locked diode lasers are highly interesting for ultra high bit rate optical telecommunication systems, because they can generate pulse trains of several GHz. These lasers have long been fabricated with quantum wells, but with quantum dots, they have shown better performances in terms of pulse duration, noise performance, and peak power. ${ }^{1}$ Mode-locking with InAs quantum dots on a GaAs substrate has indeed been demonstrated with frequencies ranging from $191 \mathrm{MHz}$ (Ref. 2) to $200 \mathrm{GHz}$, pulse durations from tens of picoseconds to $400 \mathrm{fs},{ }^{3}$ and with low noise ${ }^{4}$ and peak powers up to $15 \mathrm{~W} .{ }^{5}$ Short pulses with low noise and high peak power are important in order to achieve low error-bit rate communications.

InAs/GaAs quantum dot laser emission wavelength is normally situated in the 1-1.3 $\mu \mathrm{m}$ range and has been demonstrated to reach $1.46 \mu \mathrm{m}$, though with high threshold current. ${ }^{6}$ Much attention is now devoted to the InAs/InP material system in order to reach the $1.55-\mu \mathrm{m}$ wavelength emission required for the standards of long-haul telecommunication. This system provides quantum dots and also quantum dashes, depending on the growth procedure and the substrate orientation. The use of quantum dashes should also provide improvements over quantum wells, but at a lesser extent than quantum dots. ${ }^{7,8}$

Achievements of passive mode-locking using InAs/InP quantum nanostructures leading to high pulse repetition rate up to $346 \mathrm{GHz}$ (Ref. 9) and Fourier-limited short pulses down to 312 fs (Ref. 10) have been reported on single-section lasers. Heck et al. recently reported passive mode-locking in two-section InAs/InP quantum dot lasers up to $10.5 \mathrm{GHz}$ between $600 \mathrm{~mA}$ and $750 \mathrm{~mA}$ injection current at $10^{\circ} \mathrm{C} .^{11,12}$

While the best performances have been demonstrated using single-section lasers, multi-section lasers having at

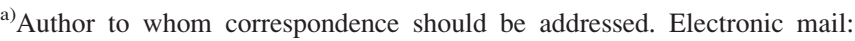
slimane.loualiche@insa-rennes.fr.
}

least one section used as a saturable absorber (SA) are normally preferred for stable operation. Through the device absorber to gain lengths ratio defined during mask processing and the reverse bias voltage applied to the SA, the modelocking can be altered to meet a specific requirement. Moreover, the mode-locked signal could be synchronized with an external reference clock, electrically modulating the absorber with the same period as the cavity round-trip time. Depending on the clock stability, this could lead to a decreased jitter.

In this paper, we report the fabrication and characterization of low threshold, passively mode-locked 4-mm and 1-mm-long two-section quantum dash lasers with short pulses and low noise.

\section{FABRICATION OF THE LASERS AND STATIC CHARACTERISATION}

The investigated semiconductor structure was grown by gas source molecular beam epitaxy (GSMBE) on InP (100) substrate. The active material consists of 5 layers of InAs quantum dashes grown using the double cap method. ${ }^{13}$ The latter consists of growing the capping layer over the dashes in two steps separated by a growth interruption under phosphorus flux to reduce the height of the highest dashes. As a result, the carrier lifetime is increased from about $700 \mathrm{ps}$ (Ref. 14) to 1600 ps (Ref. 15), leading to lower threshold current lasers. ${ }^{16,17}$ Indeed, this method should allow stacking of several layers with fewer defects. The capping layers consist of 20-nm-thick phosphide quaternary emitting at $1.18 \mu \mathrm{m}(\mathrm{PQ}(1.18))$ layers $\left(\mathrm{Ga}_{0.20} \mathrm{In}_{0.80} \mathrm{As}_{0.435} \mathrm{P}_{0.565}\right)$. The stack is centered in a 320 -nm-thick waveguide of $\mathrm{PQ}(1.18)$ cladded by InP layers (Fig. 1).

The fabricated devices are edge-emitting Fabry Perot multi-section ridge lasers. The ridge width is $2 \mu \mathrm{m}$, and the etching was done until about $100 \mathrm{~nm}$ of p-type $\mathrm{InP}$ is left above the waveguide. The electrical isolation between the sections was done by etching through the highly doped 


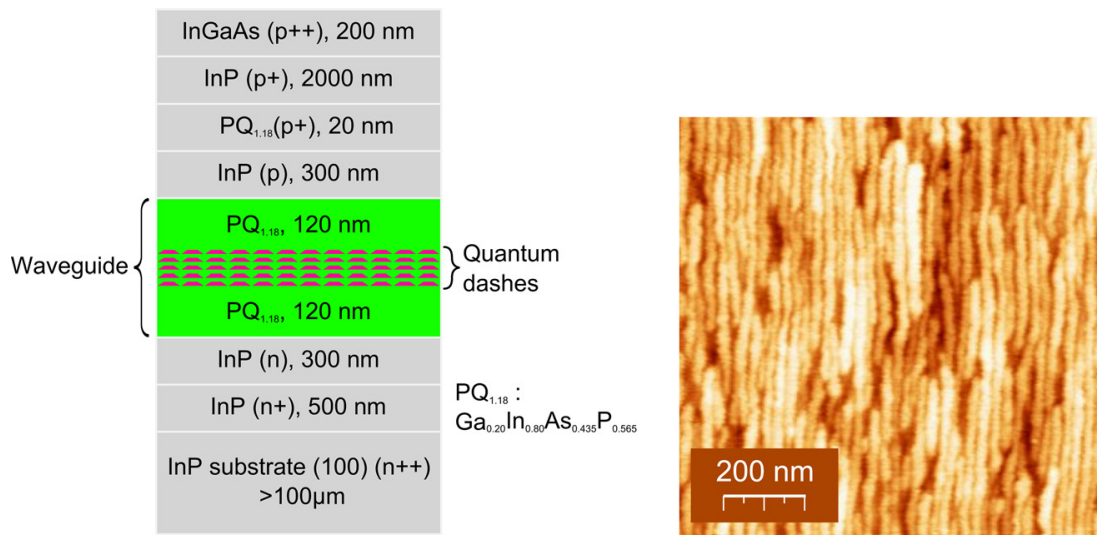

FIG. 1. (Color online) Epitaxial structure of the investigated quantum dashes and AFM picture showing $1 \times 1$ $\mu \mathrm{m}^{2}$ of the top layer of a 5-layer stack quantum dash structure fabricated with the same techniques as for the one used for the lasers presented in this paper. contact layers in a $5-\mu \mathrm{m}$ trench on top of the ridge. The length of the SA section is about 3 to $4 \%$ the total length of the laser, and the facet on its end is coated with silver for high reflectivity (Fig. 2). The SA section length ratio was chosen on the basis of a low signal absorption value of the quantum dashes. Lasers with higher ratio indeed exhibited lower output power. The low signal absorption was later measured and showed a value as high as $50 \mathrm{~cm}^{-1}$.

For characterization, the device was placed on a copper block maintained at $20{ }^{\circ} \mathrm{C}$ by means of a thermo-electric cooler. The output of the laser was coupled to a single-mode fiber (SMF) through an antireflection-coated, lensed isolator and distributed to 4 outputs for the power meter, the optical spectrum analyzer (10 pm resolution), the RF spectrum analyzer (22 GHz bandwidth), and the autocorrelator. An L-band amplifier was used for the autocorrelation measurement.

Measurements of light-current characteristics showed a threshold current of $71 \mathrm{~mA}$ for the 4-mm laser and $25 \mathrm{~mA}$ for the 1-mm one under uniform injection (Fig. 3). For all the measurements presented in this paper, the gain current was set so as to achieve a high fiber-coupled output power of 7 to $8 \mathrm{~mW}$ (Fig. 3).

\section{PASSIVE MODE-LOCKING: RESULTS AND DISCUSSION}

In this section, we report results of passive mode-locking achieved with the devices. In order to obtain mode-locking, the SA was reverse biased. This bias voltage was set so as the $\mathrm{RF}$ peak reached its highest value. As a consequence and

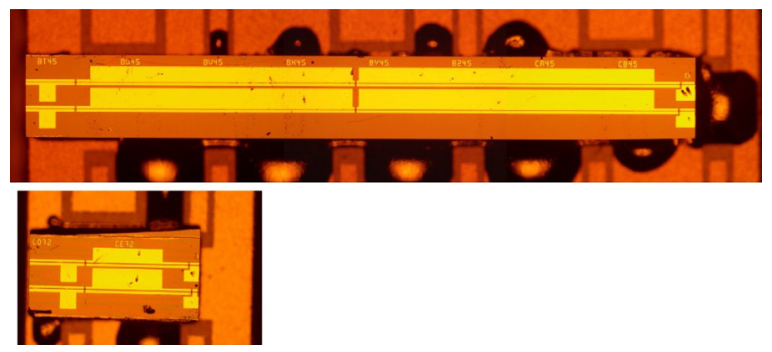

FIG. 2. (Color online) Pictures of the 4-mm and 1-mm lasers fabricated. Output facet is on the left; saturable absorber section is on the right edge. The three consecutive sections from the output facet (or two for the 1-mm laser) were shortened to make them equivalent to one section during the characterization. according to the fiber-coupled output power requirement (Fig. 3), the operating conditions applied for all the measurements presented here are a gain current of $250 \mathrm{~mA}$ with an absorber bias voltage of $-1.6 \mathrm{~V}$ for the $4-\mathrm{mm}$ laser and $140 \mathrm{~mA}$ with $-2.7 \mathrm{~V}$, respectively, for the 1-mm laser.

For the 4-mm laser, under uniform current injection, the optical spectrum measurement showed a peak at $1595 \mathrm{~nm}$ with a width of $6.7 \mathrm{~nm}$. When the reverse bias was on, the linewidth increased to $7.2 \mathrm{~nm}$. In the latter case, the appearance of smooth bumps on part of the optical spectrum (Fig. 4) and a strong increase in the RF peak indicate that partial mode-locking is happening. However, no pulse could be seen in the double background-free autocorrelation or on a fast oscilloscope, indicating that the total output power from the laser was not pulsing in a normal sense.

To further investigate the laser signal, a 1-nm bandwidth filter centered at $1600 \mathrm{~nm}$ and tuneable on a window of 20 $\mathrm{nm}$ was used. This way, autocorrelations led to the measurements of pulses ranging from 9 to $16 \mathrm{ps,} \mathrm{depending} \mathrm{on} \mathrm{the}$ part of the laser spectrum selected by the filter. The shortest pulses measured were corresponding to the extreme left and right parts of the spectrum, as seen in Fig. 5.

The result seems to match with the characteristics of strongly linear-chirped pulses. Indeed, on a linear-chirped radiation, a spectral filter is equivalent to a window on the time domain. Thus, the measured pulse width is directly related to the size of the overlapping region between the pulse and the temporal window. Selecting the edges of the mode-locked spectrum only lets the edges of the pulses pass, which yields short pulse measurements. Selecting the center yields the longest pulses.

To investigate the assumption of chirp, optical fiber was used for compensation of the unfiltered output. As a result, short pulses down to a picosecond and an RF peak increase by $10 \mathrm{~dB}$ could be measured with a standard single-mode fiber (Fig. 6), meaning that the raw pulses at the output of the laser were up-chirped. The shortest pulses were obtained using $+10.9 \mathrm{ps} / \mathrm{nm}$ external dispersion, yielding pulses of about one picosecond after deconvolution (Fig. 7), but, as seen, secondary pulses are present. This and the substructure seen in the optical spectrum show that not all the lasing modes were locked into one regime of mode-locking. The high value of external dispersion needed questions whether the usual theory of mode-locking ${ }^{18}$ underlies the actual mechanism here. 

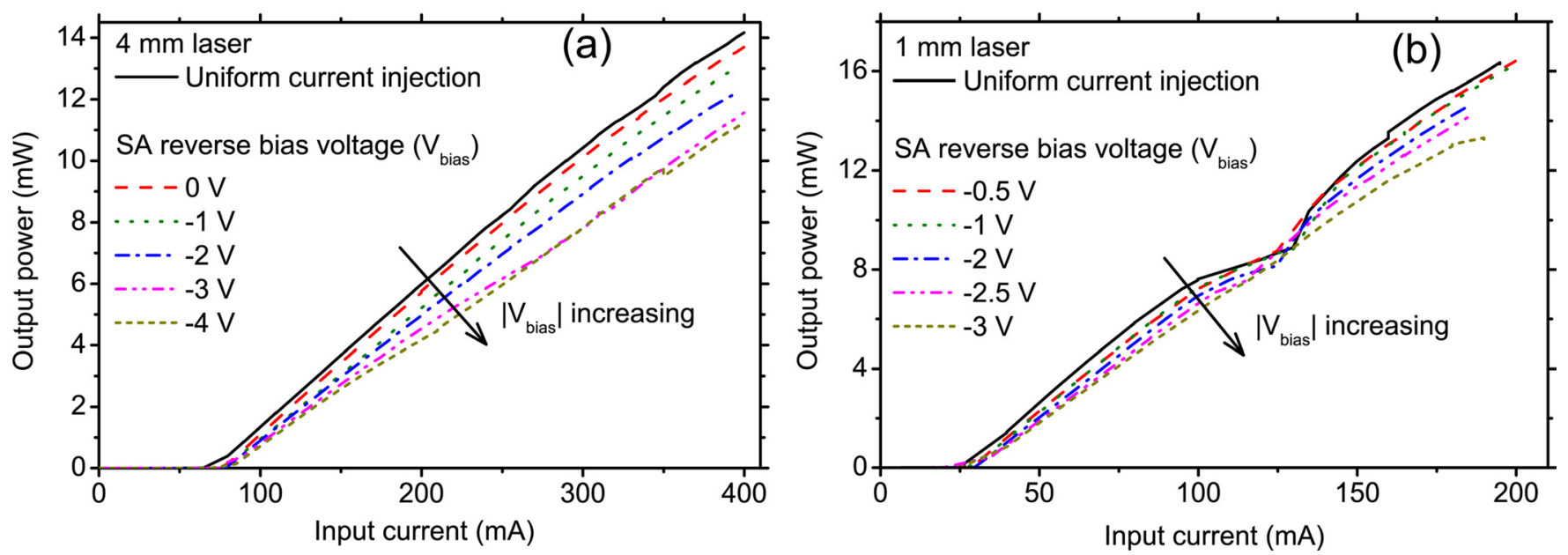

FIG. 3. (Color online) Output power vs input current under uniform injection and as a function of the reverse bias voltage over the saturable absorber (SA) for the 4-mm (a) and 1-mm (b) lasers. The black arrows represent the increase direction of the reverse bias voltage.

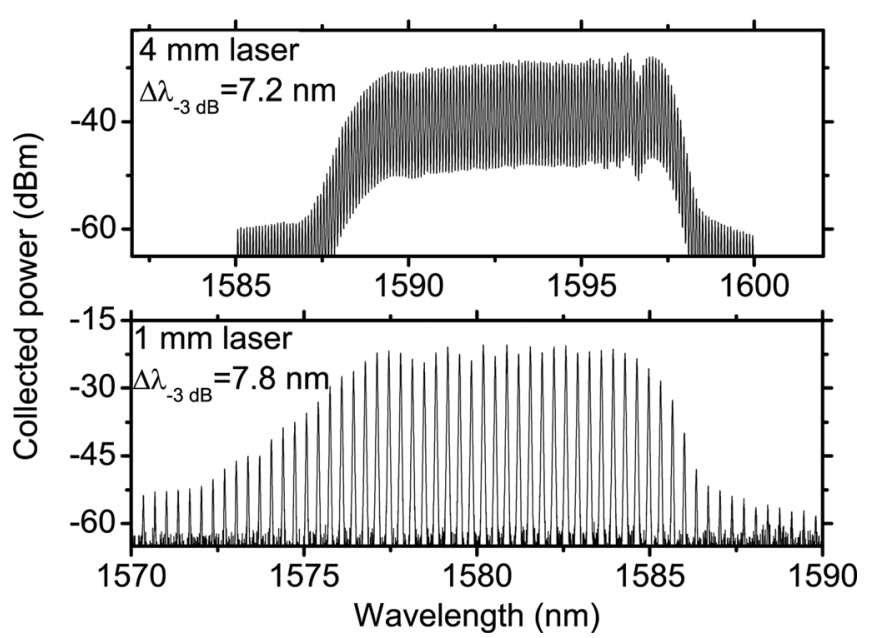

FIG. 4. Optical spectra of the 4-mm and 1-mm lasers for an output power of about $8 \mathrm{~mW}$ with absorber section reverse biased.

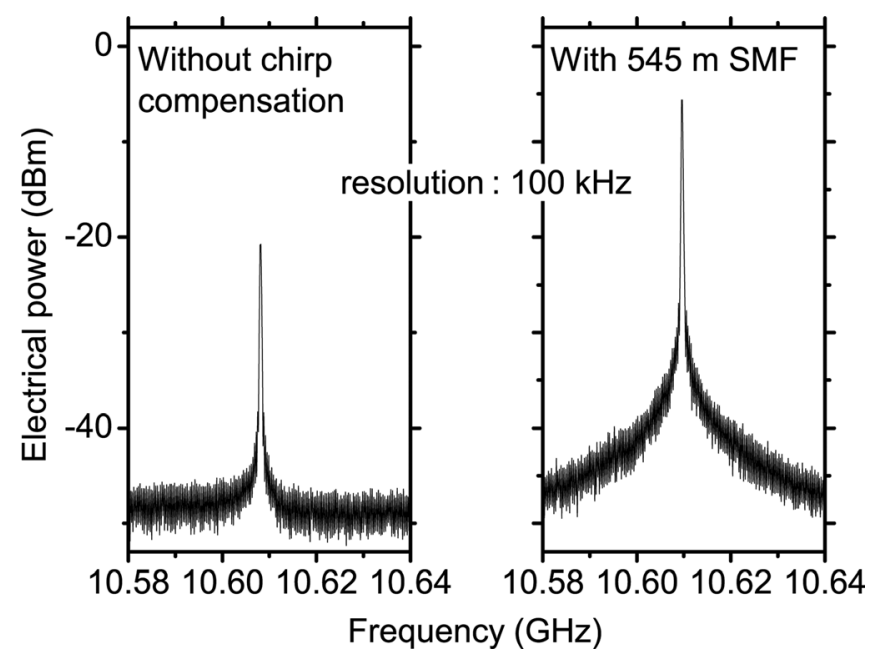

FIG. 6. RF spectra for the 4-mm laser without chirp compensation and with optimal chirp compensation.

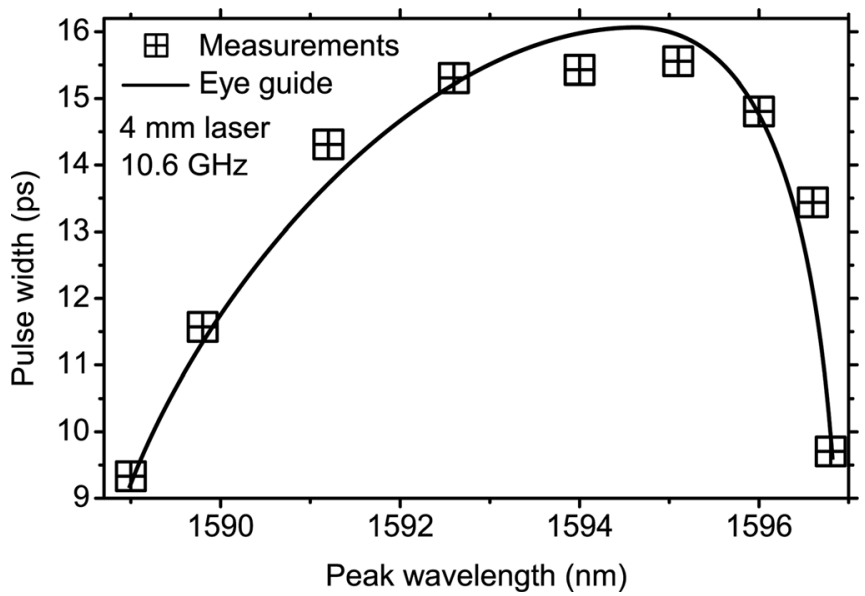

FIG. 5. Pulse width vs filter peak wavelength with eye guide for the 4-mm laser.

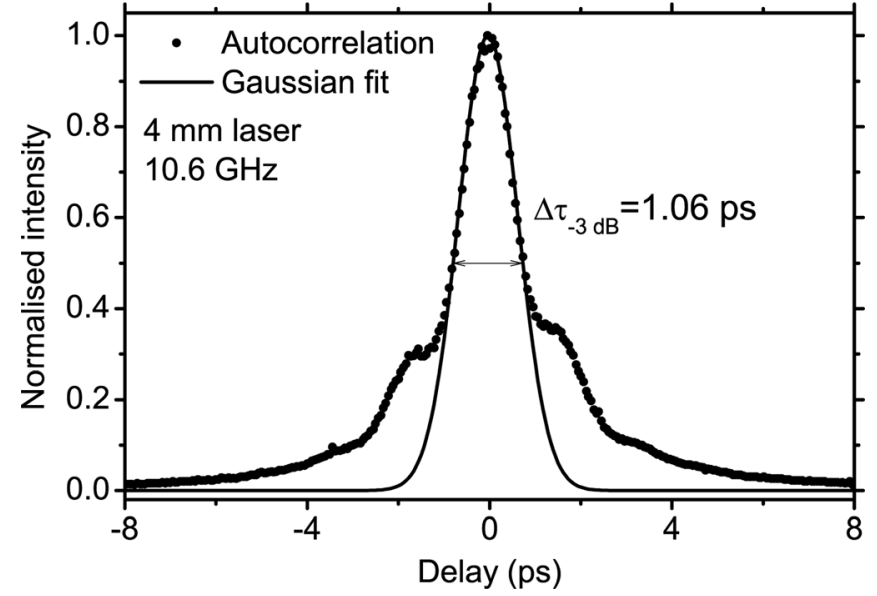

FIG. 7. Autocorrelation trace of the 4-mm laser output with $+10.9 \mathrm{ps} / \mathrm{nm}$ dispersion compensation (540 m SMF) and Gaussian fit. 


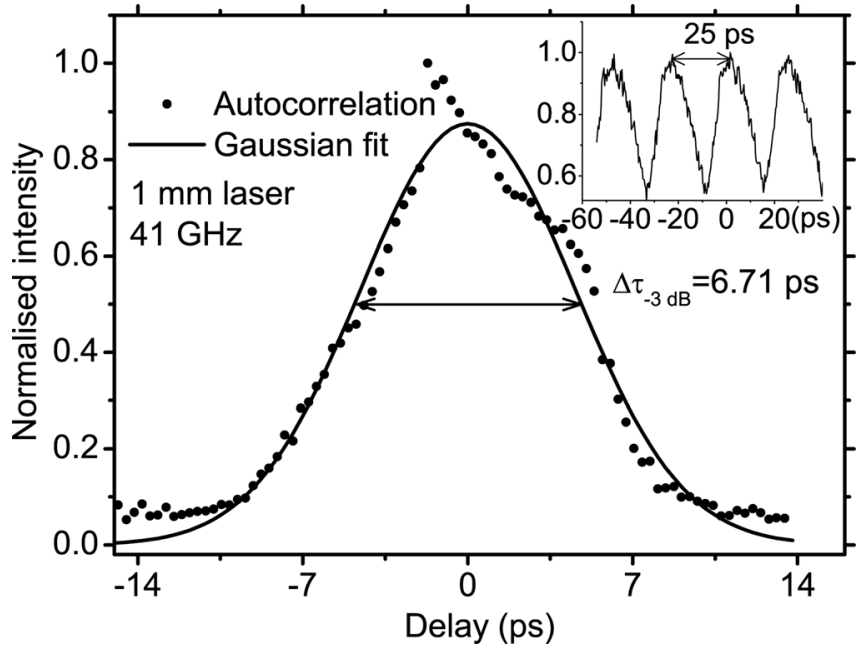

FIG. 8. Autocorrelation trace for the $1-\mathrm{mm}$ laser output with $+1.15 \mathrm{ps} / \mathrm{nm}$ dispersion compensation (60 m SMF) and Gaussian fit. Inset is the auto/ cross-correlation measurement without dispersion compensation.

Another explanation would be four-wave mixing combined with the additional non-linearity from the saturable absorber that creates coherence between adjacent modes, which, after dispersion compensation, creates a pulse.

Similarly, such investigation has also been carried out on the 1-mm laser and showed that this one also exhibits strongly chirped pulses. This time, raw pulses were detected with direct autocorrelation measurement, i.e., without any filter or fiber. Their duration is about 18 ps (Fig. 8, inset). The use of $60 \mathrm{~m}$ of single-mode fiber increased the RF peak height (Fig. 9), and the pulse duration decreased to $7 \mathrm{ps}$ (Fig. 8), thus showing that the chirp sign is the same as that of the 4-mm laser.

It should be noted that the mode-locking potential of the 4-mm laser has been investigated by the extended Lau's model. ${ }^{19}$ Results showed that, given the laser geometry, mode-locking should indeed happen with the working conditions used to obtain the results reported in this paper. The investigation is still ongoing for the $1-\mathrm{mm}$ laser.

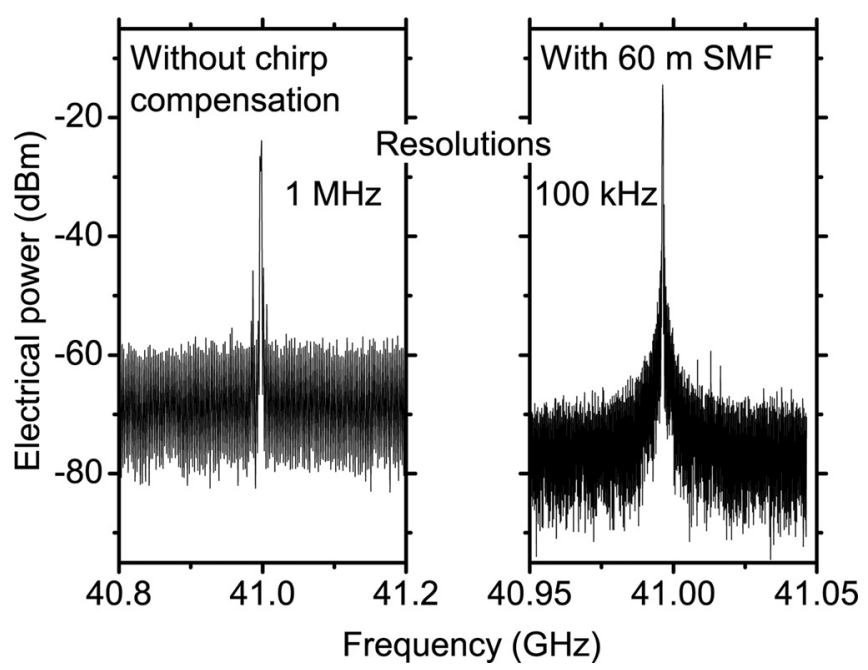

FIG. 9. RF spectra for the 1-mm laser without chirp compensation and with compensation.

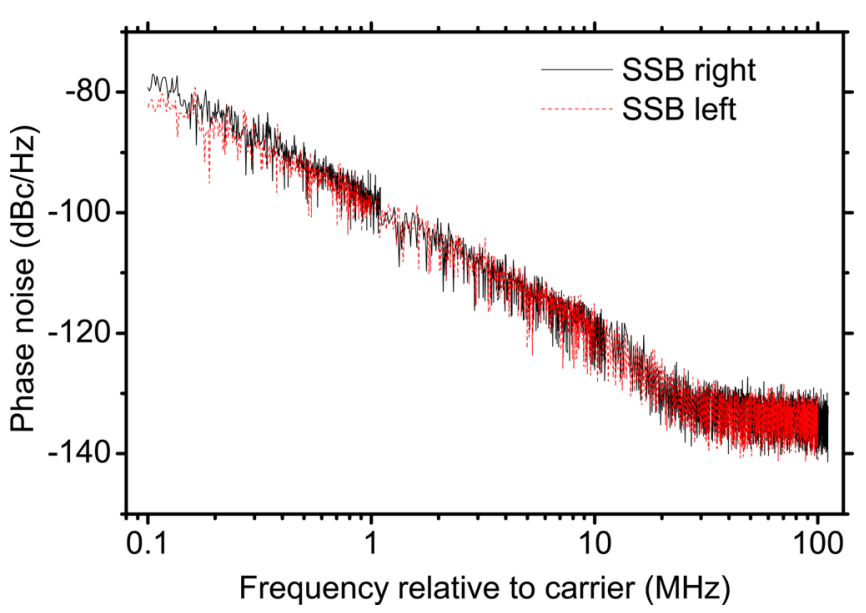

FIG. 10. (Color online) Single sideband (SSB) phase noise measurement of the 4-mm laser with $+10.9 \mathrm{ps} / \mathrm{nm}$ dispersion compensation.

\section{NOISE MEASUREMENTS FOR THE 4-MM LASER}

Noise measurements were carried out on the 4-mm laser. Results show a single side-band phase noise of -80 $\mathrm{dBc} / \mathrm{Hz}$ at $100 \mathrm{kHz}$ offset and an average timing jitter of 800 fs (Fig. 10 and Fig. 11). This is about $15 \mathrm{~dB}$ lower than what was previously reported for single quantum well lasers. ${ }^{20}$ This performance is mostly attributed to the high inversion and damping induced by the use of quantum dashes ${ }^{21}$ and probably enhanced by the use of the double cap method for the growth. Indeed, as mentioned earlier, the latter could allow the growth with fewer defects, which are known to be a source of generation-recombination noise. ${ }^{22}$

\section{CONCLUSION}

As a conclusion, mode-locking in low-threshold, twosection InAs/InP quantum dash lasers at $41 \mathrm{GHz}$ and 10.6 $\mathrm{GHz}$ was demonstrated at $1.59 \mu \mathrm{m}$. Mode-locking was suspected from the shape change of the optical spectrum. By using a tuneable filter, pulses could be measured by autocorrelation at several positions in the optical spectrum. These results supported the hypothesis of chirped pulses. By using

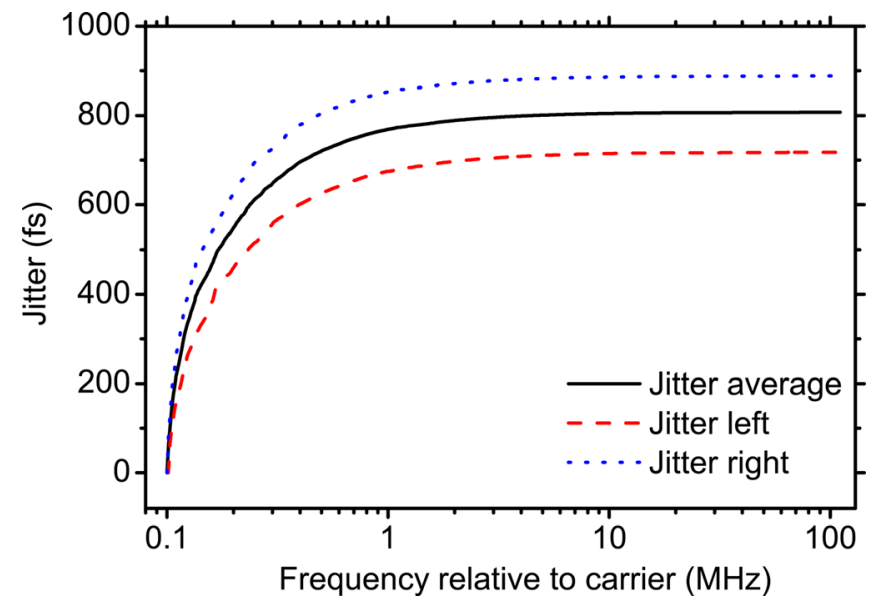

FIG. 11. (Color online) Jitter measurement of the 4-mm laser with +10.9 $\mathrm{ps} / \mathrm{nm}$ dispersion compensation. 
single-mode fiber, picosecond pulses could be measured in the 4-mm laser with a dispersion of $+10.9 \mathrm{ps} / \mathrm{nm}$ for chirp compensation, meaning that raw pulses are strongly upchirped. Noise measurement in the $10.6-\mathrm{GHz}$ laser showed that the laser exhibits, at $100 \mathrm{kHz}$ offset, $15 \mathrm{~dB}$ less noise than what was previously reported for single quantum well lasers.

\section{ACKNOWLEDGMENTS}

This work was supported by networks of Excellence ePIXnet and SANDIE and the Danish research council through the OPSCODER project.

We would like to thank Leif Oxenløwe and Michael Gallili for the use of L-band amplifiers, filters, and the high speed oscilloscope.

${ }^{1}$ M. G. Thompson, A. R. Rae, M. Xia, R. V. Penty, and I. H. White, IEEE J. Sel. Top. Quantum Electron. 15, 661 (2009).

${ }^{2}$ Y. Ding, M. A. Cataluna, D. Nikitichev, I. Krestnikov, D. Livshits, and E. U. Rafailov, Appl. Phys. Express 4, 062703 (2011).

${ }^{3}$ E. U. Rafailov, M. A. Cataluna, W. Sibbett, N. D. Il'inskaya, Y. M. Zadiranov, A. E. Zhukov, V. M. Ustinov, D. A. Livshits, A. R. Kovsh, and N. N. Ledentsov, Appl. Phys. Lett. 87, 081107 (2005).

${ }^{4}$ F. Kéfélian, S. O'Donoghue, M. T. Todaro, J. G. McInerney, and G. Huyet, IEEE Photonics Technol. Lett. 20, 1405 (2008).

${ }^{5}$ D. I. Nikitichev, M. Ruiz, Y. Ding, M. Tran, Y. Robert, M. Krakowski, M. Rossetti, P. Bardella, I. Montrosset, I. Krestnikov, D. Livshits, M. A. Cataluna, E. U. Rafailov, Conference on Lasers and Electro-optics - European Quantum Electronics Conference (CLEO Europe, EQEC), Munich, Germany, 22-26 May 2011.
${ }^{6}$ I. I. Novikov, N. Yu Gordeev, M. V. Maximov, Yu M. Shernyakov, A. E. Zhukov, A. P. Vasil'ev, E. S. Semenova, V. M. Ustinov, N. N. Ledentsov, D. Bimberg, N. D. Zakharov, and P. Werner, Semicond. Sci. Technol. 20, 33 (2005).

${ }^{7}$ Y. Arakawa and H. Sakaki, Appl. Phys. Lett. 40, 11 (1982).

${ }^{8}$ M. Asada, K. Miyamoto, and Y. Suematsu, IEEE J. Quantum Electron. 22, 9 (1986).

${ }^{9}$ K. Merghem, A. Akrout, A. Martinez, G. Aubin, A. Ramdane, F. Lelarge, and G.-H. Duan, Appl. Phys. Lett. 94, 021107 (2009).

${ }^{10}$ Z. G. Lu, J. R. Liu, S. Raymond, P. J. Poole, P. J. Barrios, and D. Poitras, Opt. Express 16, 10835 (2008).

${ }^{11}$ M. J. R. Heck, E. A. J. M. Bente, B. Smalbrugge, Y.-S. Oei, M. K. Smit, S. Anantathanasarn, and R. Nötzel, Opt. Express 15, 16292 (2007).

${ }^{12}$ M. J. R. Heck, A. Renault, E. A. J. M. Bente, Y.-S. Oei, M. K. Smit, K. S. E. Eikema, W. Ubachs, S. Anantathanasarn, and R. Nötzel, IEEE J. Sel. Top. Quantum Electron. 15, 634 (2009).

${ }^{13}$ C. Paranthoen, N. Bertru, O. Dehaese, A. Le Corre, S. Loualiche, B. Lambert, and G. Patriarche, Appl. Phys. Lett. 78, 1751 (2001).

${ }^{14}$ S. Hinooda, S. Fréchengues, B. Lambert, S. Loualiche, M. Paillard, X. Marie, and T. Amand, Appl. Phys. Lett. 75, 3530 (1999).

${ }^{15}$ P. Miska, J. Even, O. Dehaese, and X. Marie, Appl. Phys. Lett. 92, 191103 (2008).

${ }^{16}$ E. Homeyer, R. Piron, F. Grillot, O. Dehaese, K. Tavernier, E. Mace, J. Even, A. Lecorre, and S. Loualiche, Jpn. J. Appl. Phys. 46, 6903 (2007).

${ }^{17}$ D. Zhou, R. Piron, M. Dontabactouny, O. Dehaese, F. Grillot, T. Batte, K. Tavernier, J. Even, and S. Loualiche, Electron. Lett. 45, 1 (2009).

${ }^{18}$ H. A. Haus, Jpn. J. Appl. Phys. 20, 1007 (1981).

${ }^{19}$ C.-Y. Lin, Y.-C. Xin, Y. Li, F. L. Chiragh, and L. F. Lester, Opt. Express 17, 22 (2009).

${ }^{20}$ K. Yvind, D. Larsson, L. J. Christiansen, J. Mørk, J. M. Hvam, and J. Hanberg, Electron. Lett. 40, 12 (2004).

${ }^{21}$ T. W. Berg and J. Mørk, Appl. Phys. Lett. 82, 18 (2003).

${ }^{22}$ G. Hu, J. Li, Y. Shi, and J. Shi, Opt. Laser Technol. 39, 165 (2007). 